Article

\title{
Biomimetic Superhydrophobic Hollowed-Out Pyramid Surface Based on Self-Assembly
}

\author{
Weipeng Luo ${ }^{1, *(\mathbb{D})}$, Bin $\mathrm{Yu}^{2}$, Dingbang Xiao ${ }^{1, *}$, Meng Zhang ${ }^{1}$, Xuezhong $\mathrm{Wu}^{1}$ and Guoxi Li ${ }^{1, *}$ \\ 1 College of Mechatronics Engineering and Automation, National University of Defense Technology, \\ Changsha 410073, China; z.mengdr@gmail.com (M.Z.); xzw@nudt.edu.cn (X.W.) \\ 2 QuantumCTeK Co., Ltd., Hefei 230031, China; xpp105106@126.com \\ * Correspondence: luoweipeng09@nudt.edu.cn (W.L.); xiaodb0623@163.com (D.X.); lgx2020@sina.com (G.L.); \\ Tel.: +86-150-8478-6986 (W.L.)
}

Received: 31 March 2018; Accepted: 14 May 2018; Published: 16 May 2018

\begin{abstract}
In this paper, we present a periodic hollowed-out pyramid microstructure with excellent superhydrophobicity. In our approach, T-topping pillars and capillary-induced self-assembly methods were combined with the photolithography process to fabricate a hollowed-out pyramid structure. First, a wideband ultraviolet source without a filter was used to fabricate the T-topping pillars during the exposure process; then, the evaporation-induced assembly collapsed the pillars and formed the hollowed-out pyramid structure. Scanning electron microscopy images showed the microstructures of the prepared surface. The contact angle of the surface was $154^{\circ}$. The surface showed excellent high temperature and ultraviolet irradiation tolerance, and the contact angle of the surface barely changed when the temperature dropped. This excellent environmental durability of our superhydrophobic surface has potential applications for self-cleaning and friction drag reduction under water.
\end{abstract}

Keywords: superhydrophobic; biomimetic; self-assembly; SU-8 photoresist

\section{Introduction}

Friction drag is an important factor for marine vehicles. Drag reduction techniques have become a focus to increase vehicle speed and save fuel. Several techniques have been proposed to reduce the friction drag, including water repellent walls [1,2], microbubbles [3,4], surface microstructure [5], and surfactant additives [6].

Bionics and experiments showed that superhydrophobic surfaces have an obvious drag reduction effect due to the ability to retaining microbubbles [1,7-9]. The retention of microbubbles on the surfaces can reduce friction drag by flowing slipping. However, the microbubbles disappear rapidly because of dissolution and scouring by water. Increasing the number of resident microbubbles has become an important issue.

The Salvinia molesta leaf has excellent superhydrophobicity and air-retaining properties under water because of its hollowed-out pyramid-like structure [10]. Hence, we focused on fabricating a superhydrophobic surface with a hollowed-out pyramid-like structure. Evaporation-induced assembly of pillars was used to fabricate the structure. A variety of factors that may affect the self-assembly process have been studied at the micrometer scale [11-16]. Capillary force was found to be the most important factor. The assembly process was considered as a competition between elasticity and capillarity for wet micropillar systems $[17,18]$. Capillary force on an individual pillar in a system of four pillars was explored by Chandra [19]. Adhesion force and capillary force are the major factors used to bend the ultra-high aspect ratio silicon (Si) nanowires [20]. 
Adhesion between the micro pillars is another important factor that determines the final assembly [21]. A polymer solution was used to provide an adhesion force between the pillars and to improve the self-assembly stability [22]. Laser printing has been used to make micro pillars, and the collapsed structure was formed by self-assembly [23].

Inclined lithography was also used to fabricate sloping micro structures [24,25]. Sloping micro structures have been fabricated using negative thick photoresist such as SU-8 [26-28]. Inclined lithography can be used to create the hollowed-out pyramid-like structure, requiring incline lithography in four different directions and an exposure machine to adjust the tilted angle of the stage. However, performing alignment to ensure the adjacent micro pillars join together is difficult.

These studies built a strong foundation for fabricating hollowed-out pyramid-like structures. In this paper, we fabricated a superhydrophobic surface based on the hollowed-out pyramid-like microstructure. Since the discovery of the lotus effect, the preparation of the biomimetic superhydrophobic surfaces has aroused considerable interest among researchers. From observation and preparation, wettability was found to be related to the surface free energy and structure roughness.

Inspired by the plants and animals in nature, scientists fabricate numerous biomimetic superhydrophobic surfaces via various smart materials routes to construct rough surfaces and low-free-energy materials [29-31]. The major works focused on creating super-hydrophobic surfaces by modifying low-surface-energy groups, such as fluorinate and fluoroalkyl silaneor [32,33]. Some studies focused on the fabrication and application of hydrophobic membranes [34-36]. Non-fluorinated hydrophobic grafting molecules were used to modify hydrophilic ceramic membranes $[35,36]$. Others have changed the microstructure of the surfaces, including chemical etching and periodic arrays made using the micro-electromechanical systems (MEMS) process. Usually, the two methods are combined to make superhydrophobic surfaces.

Using the periodic array microstructures, superoleophobic and superrepellent surface fabrication has been achieved [37,38]. A T-structure pillar can change the geometric edge angle of the straight wall pillar, which can cause droplet overhang on the T-structure pillar array surface. Additionally, the nanoscale doubly reentrant structure considerably improves the wettability of the surface, which can make the prepared surface of any material superrepellent [38].

The durability of superhydrobic surfaces is another important aspect. Poor durability limits the practical applications. Mechanical abrasion, chemical stability, organic solvents, high temperature. and ultraviolet (UV) irradiation are harsh conditions for superhydrobic surfaces. Many durable superhydrobic surfaces have been fabricated [39-45], and even self-recovering superhydrophobic coatings have been reported $[46,47]$. A superhydrophobic cotton fabric with excellent washing durability, solvent resistance, and chemical stability was prepared from an SU-8 derived coating, the water contact angle was $163^{\circ}$, and the sliding angle was $2^{\circ}$ [41]. A simple dip coating approach was reported for preparing super durable superhydrophobic materials; the mechanical abrasion, long time immersion in various liquids, and repeated washing had no obvious influence on the superhydrophobicity [44]. Most research focused on fabricating self-cleaning surfaces with superior mechanical abrasion, chemical, and UV resistance, but the effect of temperature changes on the wettability of the surfaces must be researched.

In this paper, we combined the T-topping structure and capillary-induced self-assembly in the photolithography process. Only the geometry structure of the surface was changed without addition of low surface-energy ingredients. The contact angle of the surface was $154 \pm 2^{\circ}$, the sliding angle of the surface was $10 \pm 1^{\circ}$. The sample showed excellent wettability after high temperature thermal treatment and ultraviolet irradiation. The contact angle of the surface fluctuated slightly in the cooling process. The interspace surrounded by the hollowed-out pyramid-like structures was better for air retention under water, allowing the surface to have potential for drag reduction under water. 


\section{Materials and Methods}

\subsection{Materials}

In this study, all chemicals were used as received. The SU-8 2100 Negative Photoresist and SU-8 developer were purchased from Micro Chem (Westborough, MA, US). Other chemicals, including ethanol $\left(\mathrm{C}_{2} \mathrm{H}_{5} \mathrm{OH}\right)$, acetone $\left(\mathrm{C}_{3} \mathrm{H}_{6} \mathrm{O}\right)$, and Isopropyl Alcohol (IPA) were purchased from Sinopharm (Shanghai, China). Silicon (Si) slides with $500 \mathrm{~nm}$ thick silicon dioxide were used as the substrate. Ultrapure water obtained from a Millipore Milli-Q system (resistance rate $>18.2 \mathrm{M} \Omega \cdot \mathrm{cm}$ ) was used for sample preparation. The mask plate was manufactured by Shenzhen Newway Photomask making Co., Ltd. (Shenzhen, China).

\subsection{T-Topping Pillar Preparation}

Many researchers improved the fabrication technology to avoid the T-topping effect of SU-8 structure fabrication [48-50]. However, the T-topping pillar was the key structure here. Because the contact angle of SU-8 film is just $82^{\circ}$, it is insufficient for straight wall pillars to sustain droplet in the Cassie state. The T-topping pillar allowed the surface to sustain water in the Cassie state [51]. The graphic on the mask plate was an array of circles in two dimensions. The period was $100 \mu \mathrm{m}$ and the diameter of the circle was $20 \mu \mathrm{m}$. The specific fabrication steps were as follows: (1) Ultrasonic cleaner (KQ-800KDB, Kunshan Ultrosonic instrument Co., Ltd., Kunshan, China) was used to wash the silicon wafer. The wafer was washed with acetone, ethanol, and deionized water. The washing time for each solution was $5 \mathrm{~min}$. Then the wafer was dried in the air and cleaned by oxygen plasma. The SU-8 photoresist was heated to $40^{\circ} \mathrm{C}$ and maintained at this temperature for $30 \mathrm{~min}$ to decrease the viscosity and remove the air bubbles. (2) The SU-8 photoresist was poured on the prepared wafer, and the wafer was spin-coated at $3000 \mathrm{rpm}$ for $20 \mathrm{~s}$ using a spinner (EL-S-200TT, Obducat, Radolfzell, Germany). The thickness of the SU-8 film was about $100 \mu \mathrm{m}$. Then the sample was prebaked at $65^{\circ} \mathrm{C}$ for $10 \mathrm{~min}$ to evaporate the organic solvent on the hotplate (KW-4AH, Chemat technology Inc., Northridge, CA, US). Finally, the SU-8 developer was used to decrease the marginal thick part of the SU-8 film. (3) The mask plate was placed upon the wafer with Su-8 film, then the sample was exposed for $30 \mathrm{~s}$ to the UV source at an exposure dose of $8 \mathrm{~mW} / \mathrm{cm}^{2}$. A wideband ultraviolet source without a filter was used in the exposure step to obtain T-topping pillars. (4) The sample was baked at $95{ }^{\circ} \mathrm{C}$ for $10 \mathrm{~min}$ on the hotplate and developed in the SU-8 developer for $6 \mathrm{~min}$. Then the wafer sample was rinsed in the deionized water. Finally, the prepared sample was dried in the air naturally.

\subsection{Preparation of Mask Plate for the Hollowed-Out Pyramid-Like Structure}

The mask graphic was an array of units composed by four adjacent circles in two dimensions. The parameters of the mask graphic were calculated and designed. As shown in Figure 1, the area surrounded by the red line was a repeat unit of the array. The unit was composed of four adjacent circles, $\mathrm{P}$ is the array period, $\mathrm{L}$ is the distance of the two adjacent circles, and $\mathrm{D}$ is the diameter of a single circle. According to the previous studies of hydrophobicity and self-assembly, the parameters of the mask graphic were chosen as: $\mathrm{P}=100 \mu \mathrm{m}, \mathrm{L}=50 \mu \mathrm{m}$, and $\mathrm{D}=10 \mu \mathrm{m}$. 


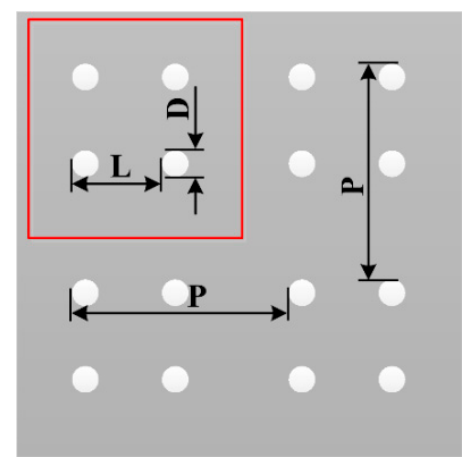

Figure 1. Schematic illustrations of the mask plate. The area surrounded by the red line is the unit of the array. The unit was composed of four adjacent circles. P is the array period $(100 \mu \mathrm{m}), \mathrm{L}$ is the distance of the two adjacent circles $(50 \mu \mathrm{m})$, and $\mathrm{D}$ is the diameter of a single circle $(10 \mu \mathrm{m})$.

\subsection{Hollowed-Out Pyramid-Like Structure Preparation}

All steps were identical to the T-topping pillar preparation. The only difference was the last step of structure release. The details are shown in Figure 2. When the surface sample was removed from water after the development process, the micro pillars had formed, with water filling the space around the pillars. The water surrounded by the four adjacent pillars (in the repeated unit) evaporated more slowly. With the water evaporating, a liquid bridge formed between the four adjacent pillars. With the evaporation of the water, the capillary force made the top of the adjacent pillars join together. The pillars collapsed to the periodic hollowed-out pyramid array structure by self-assembly.

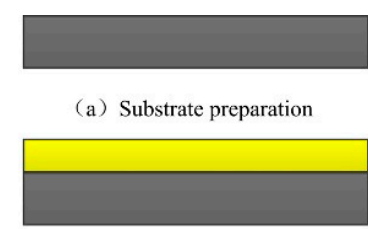

(b) Spin coating

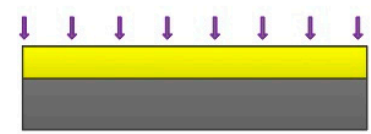

(c) Lithographic exposure

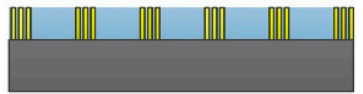

(d) Development

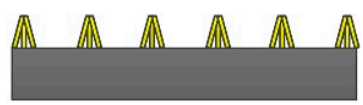

(e) Structure release

Silicon

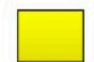

SU-8

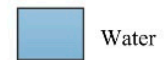

Figure 2. Schematics of the procedures of fabricating superhydrophobic surface with hollowed-out pyramid array structures. (a-e) The lithography procedures, including substrate preparation, spin-coating, exposure, development, and structure release. (d,e) The vertical section view that was cut though the center of the hollowed-out pyramid microstructure; three pillars are visible.

\subsection{Characterization}

The morphologies of the solid phase nanostructures were investigated using field emission scanning electron microscopy (FESEM; Hitachi S-4800, Hitachi Ltd., Tokyo, Japan) at $5 \mathrm{kV}$. The static contact angles of the sample were measured by the contact angle measurement instrument. Contact angle images were collected with a high-resolution camera, and the tangent lines were drawn using Microsoft Visio 2010 (Microsoft, Redmond, WA, USA). Then, the contact angles were measured using a protractor, with an accuracy of $\pm 2^{\circ}$. Water droplets of about $7 \mu \mathrm{L}$ were dropped on the sample from a distance of $0.3 \mathrm{~cm}$ by vibrating the pipette. The sliding angles were measured with the assistance of a rotatable platform with an angle scale, with an accuracy of $\pm 1^{\circ}$. 


\subsection{Temperature Durability Test}

The wettability of the sample under harsh environments was tested, including high and low temperatures. In the high temperature durability tests, the sample was $20 \times 20 \mathrm{~mm}^{2}$. The sample was heated by a hotplate. First, the sample was placed on the hotplate for $1 \mathrm{~h}$ at $100^{\circ} \mathrm{C}$; next, the sample was removed and cooled to room temperature; third, the contact angles of the sample were measured and then the sample was placed back on the hotplate for another $1 \mathrm{~h}$ at $100{ }^{\circ} \mathrm{C}$. The process was repeated 8 times. Finally the temperature of the hotplate was set to $150^{\circ} \mathrm{C}$, and the experiment above was repeated.

In the cooling tests, the sample was $20 \times 20 \mathrm{~mm}^{2}$. The relationship between the static contact angles and the temperature was investigated. The sample was cooled by a ZL-04AGT thermostat (ESPEC, Osaka, Japan). The sample was placed on a refrigeration table, and the contact angle measurement instrument was placed in the thermostat to shoot the side view of the water droplet. The temperature fell from 10 to $-5^{\circ} \mathrm{C}$, and the cooling rate was $3{ }^{\circ} \mathrm{C} / \mathrm{min}$. The humidity was $30 \%$.

\subsection{UVDurability Test}

In the UV durability tests, the UV source (laser power $8 \mathrm{~mW} / \mathrm{cm}^{2}, \mathrm{k}=365 \mathrm{~nm}$ ) of the lithography machine (ABM Inc., San Jose, CA, USA) was used for irradiation. The distance between the UV light source and the samples was about $5 \mathrm{~cm}$. The samples were placed in the UV chamber for up to $90 \mathrm{~min}$ and the contact angles of the sample were measured every $10 \mathrm{~min}$.

\section{Results and Discussion}

\subsection{T-Topping Pillar}

To fabricate the T-topping pillar, a wideband UV source without a filter was used in the exposure process. The microstructure was characterized by a scanning electron microscope (SEM). As shown in Figure 3, the diameter of the top was $34.2 \mu \mathrm{m}$, the diameter of the end was $25 \mu \mathrm{m}$, and the length of the extended part of the T-topping pillar was $2.9 \mu \mathrm{m}$. The geometrical edge angle of the straight wall pillar was $90^{\circ}$. The contact angle of the SU-8 film was tested by a contact angle measuring device. The result showed the contact angle of the SU-8 film was $82^{\circ}$, which is insufficient for the straight wall pillar surface to sustain droplets in the Cassie state. However, the T-topping structure changes the geometrical edge angle of the straight wall pillar from $90^{\circ}$ to $0^{\circ}$, enabling the droplet in Cassie state on the prepared surface if the intrinsic water contact angle of the surface is larger than $0^{\circ}$.

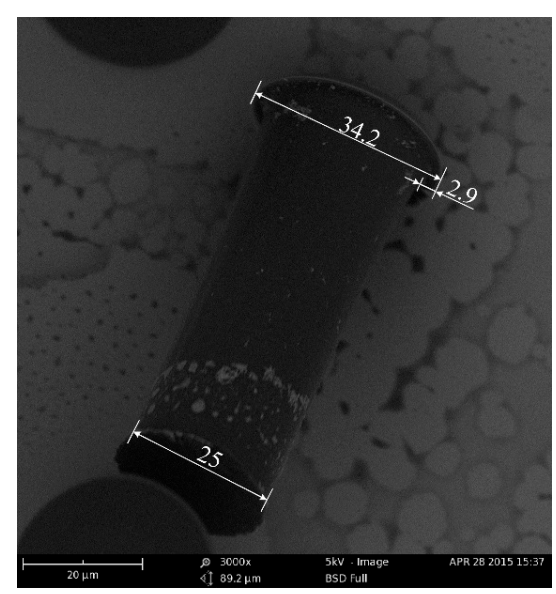

Figure 3. Scanning electron microscope (SEM) image showing the microstructure of the T-topping pillar. The diameter of the top is $34.2 \mu \mathrm{m}$, the diameter of the bottom is $25 \mu \mathrm{m}$, and the length of the top part of the T-topping is $2.9 \mu \mathrm{m}$. 
Gap and wavelength were the key factors to control the error of the SU-8 structure [49]. The small gap between the photo mask and photoresist reduced the diffraction error. Because the thick SU-8 film was not absolutely flat, controlling the gap homogeneity between photo mask and resist was hard. The other key factor was the exposure wavelength. If the wavelength was shorter than $350 \mathrm{~nm}$, the top region was strongly exposed. The redundant acid would diffuse during the post exposure bake stage, and lead to a T-topping.

\subsection{Effect of Structural Parameters}

Droplet on the T-topping pillar array surface is in Cassie state. Then the apparent contact angle $\theta_{c}$ for a suspended droplet is described by the Cassie-Baxter [51] model:

$$
\cos \theta_{\mathrm{c}}=\mathrm{f}_{\mathrm{s}}\left(\cos \theta_{\mathrm{y}}+1\right)-1
$$

where $\theta_{\mathrm{c}}$ is the apparent contact angle on the textured surface, $\mathrm{f}_{\mathrm{s}}$ is the fraction of the real liquid-solid contact area to the entire interface, and $\theta_{\mathrm{y}}$ is the equilibrium contact angle on the smooth surface.

The contact angle on the smooth SU-8 film was $82^{\circ}$, so the apparent contact angle $\theta_{\mathrm{c}}$ is a function of $\mathrm{f}_{\mathrm{s}}$ according to Equation (1). A typical plot of $\theta_{\mathrm{c}}$ (Figure 4) shows that as $\mathrm{f}_{\mathrm{s}}$ decreases, the apparent contact angle of the surface increases. The dashed line indicates the value of $\mathrm{f}_{\mathrm{s}}$ at $\theta_{\mathrm{c}}=150^{\circ}$. If $\mathrm{f}_{\mathrm{s}}<11.76 \%$, $\theta_{\mathrm{c}}$ is above $150^{\circ}$.

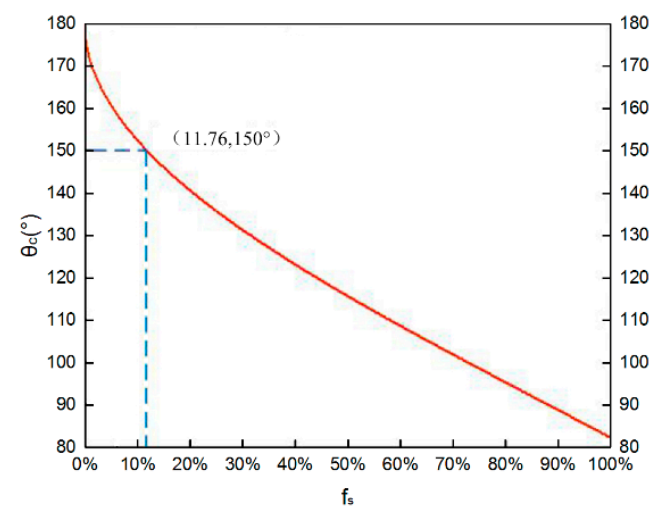

Figure 4. Apparent contact angle $\left(\theta_{c}\right)$ of the textured SU-8 surface as a function of the fraction of the real liquid-solid contact area to the entire interface $\left(f_{s}\right)$. As $f_{s}$ decreases, the apparent contact angle $\theta_{c}$ of the surface increases to $150^{\circ}$. The dashed line indicates the value of $f_{s}$ at $\theta_{c}=150^{\circ}$.

For the structure we designed, considering the water drop contact with $\mathrm{N}$ hollowed-out pyramid-like unit-cells, the real liquid-solid contact area is $S_{r}=4 N \pi(D / 2)^{2}$ and the entire liquid-solid interface area is $\mathrm{S}=\mathrm{NP}^{2}$. Then, the fraction of the solid contact with the liquid is

$$
\mathrm{f}_{\mathrm{S}}=\pi \mathrm{D}^{2} / \mathrm{P}^{2}
$$

If $\mathrm{D} / \mathrm{P}<0.19, \theta_{\mathrm{c}}$ is above $150^{\circ}$ and the surface becomes superhydrophobic. However, with decreasing $\mathrm{f}_{\mathrm{s}}$, we wanted to determine if contact angle would increase. According to a previous study [19], if the $f_{S}$ deceases until $F_{C}>F_{E}$ during the entire self-assembly $\left(F_{C}\right.$ is the capillary force, and $\mathrm{F}_{\mathrm{E}}$ is the elastic restore force), the micropillars will be unstable. The micro pillars will randomly collapse.

The parameters of the micro structure influence the self-assembly process. The capillary force must be large enough to bend the pillars against each other. The height and diameter determine the stiffness of the micro pillar. Short and large diameters make the pillars hard to bend. Large and small diameters make the micro pillar easy to bend, which means it is hard for the micro pillars to resist 
random interference. Hence, proper ratio of height and diameter is very important. The capillary force on an individual pillar in a system of four pillars has been explored [19,23], and was used for structure calculations. Because the capillary force during the self-assembly is complicated and time-varying, providing a precise formula is hard. Previous studies only provided an approximate formula after simplification. According to these studies, we calculated and estimated the structure parameters near the real critical value. For testing, the optimal numerical parameters need more theoretical analysis and experimentation.

The distance of the two adjacent pillars $\mathrm{L}$ is important for the stability of self-assembly as it determines the displacement of the top of the pillars. According to previous studies, as the distance between two adjacent pillars decreases, $\mathrm{F}_{\mathrm{C}}$ increases, and $\mathrm{F}_{\mathrm{E}}$ decreases. This facilitates self-assembly, and improves the stability of self-assembly.

\subsection{Surface Morphology}

Surface morphology is very important for the wettability of a surface. The microstructures were characterized by SEM. Figure 5a shows the top view of the fabricated microstructures: an array of hollowed-out pyramid-like unit-cells. The unit-cell is composed of four adjacent pillars. The distance between two adjacent periodic unit-cells was $100 \mu \mathrm{m}$, and the diameter of the top of the single pillar was about $15 \mu \mathrm{m}$, and the diameter of the bottom of the pillar was about $11 \mu \mathrm{m}$. Because only the four circles on the top contact the droplet of water, the fraction of the solid in contact with liquid is about $7.07 \%$. Thus, the static contact angle should be larger than $150^{\circ}$ according to the Cassie-Baxter model. From Figure 5b, we obtained the whole image of the fabricated superhydrophobic microstructure. The periodic unit-cell was a hollowed-out pyramid structure like the top of the Salvinia molesta leaf. The bottom of the pyramid-like structure was square and the side length was $50 \mu \mathrm{m}$. Thus, we successfully performed the difficult fabrication process and created the hollowed-out pyramid-like structure. The wettability of the sample was measured. The water drop on the surface was about $7 \mu \mathrm{L}$, and the static contact angle was $154 \pm 2^{\circ}$. The water drop used to test the sliding angle was about $10 \mu \mathrm{L}$, and the sliding angle of the surface was $10 \pm 1^{\circ}$.

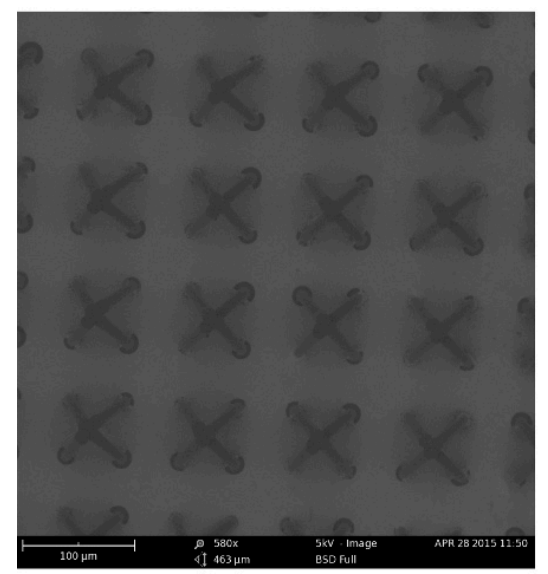

(a)

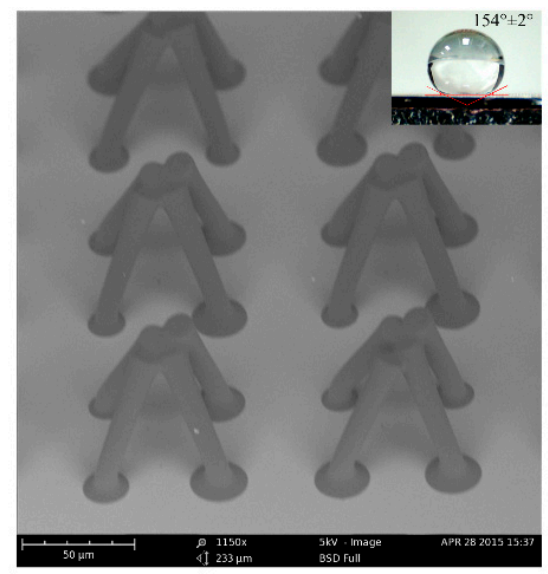

(b)

Figure 5. SEM images of the hollowed-out pyramid-like arrays. (a) Top view of the hollowed-out pyramid-like arrays; the top of the adjacent pillars are obviously joined together; (b) a $45^{\circ}$-tilted view of the hollowed-out pyramid-like surface. (Inset) A droplet of water on top of the prepared surface. The water drop on the surface was about $7 \mu \mathrm{L}$, and the static contact angle was $154 \pm 2^{\circ}$.

Adhesive force is required to bond the microstructures after collapse, which was proven again by our study. Polymer weld was examined to bond the micro pillars [22,52]. Although the liquid bridge could pull the four adjacent micro pillars close together, a strong force is still required to bond the 
pillars together after the water evaporated completely. As shown in Figure 6, some SU-8 adhered on the pillars during the last process of development; the remaining SU-8 photoresist bonds the four adjacent micro pillars together.

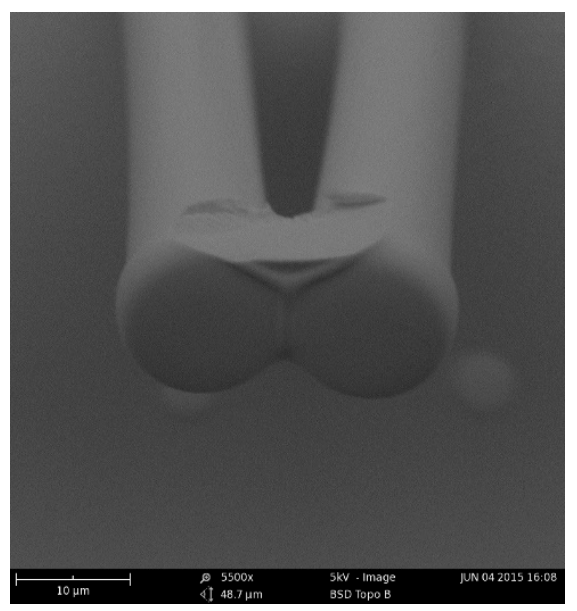

Figure 6. SEM image showing the remaining SU-8 photoresist bonding formation around the micro pillars. Two pillars remain. The fracture of the structure shows the remaining SU-8 photoresist bonds the four adjacent micro pillars together.

The rate of water evaporation is a key factor for bond formation. We placed the sample in the oven at $50^{\circ} \mathrm{C}$ to accelerate the evaporation rate, no bond formed, and the collapsed pillars reverted back to their upright position after complete evaporation. Additionally, when the sample was placed in a closed glass container at $20^{\circ} \mathrm{C}$ to slow the evaporation rate, the result was the same, showing that a proper evaporation rate is important for self-assembly. This area requires further research.

For superhydrophobic surfaces, structure defects are unacceptable. A small defect could make the Cassie state of the droplet break down. However, obtaining a defect-free sample is difficult. Many factors affect the self-assembly process, especially the bond strength between the wafer and the micro pillars.

The bond strength between the wafer and the micro pillars is the essential factor that can provide the force that the pillars need to stay standing. If the bond strength is rather small, the micro pillars will fall down, or even flow away during the developing process. Several approaches to achieve adhesion between the wafer and the micro pillars are possible, such as wet etching with the solution mixed by $\mathrm{H}_{2} \mathrm{SO}_{4}$ and $\mathrm{H}_{2} \mathrm{O}_{2}$, cleaning by oxygen plasma, or pre-spin coated with Polymethyl Methacrylate (PMMA). Obviously, the wet etching process can't be used for metal basement. Damp bottom are extremely harmful for the bond strength, so baking the bottom in the oven for a period of time to maintain dryness is necessary before spin coating the SU-8.

\subsection{Environmental Stability}

The wettability of the sample under severe environmental conditions was tested. To test the high temperature durability of the surface, the sample was placed on a hotplate at $100{ }^{\circ} \mathrm{C}$ for one hour. Then the sample was removed from the hotplate and cooled to room temperature. The contact angles were tested, and the sample was placed back on the hotplate at $100^{\circ} \mathrm{C}$ for another hour. This process was repeated eight times. The temperature was then raised to $150^{\circ} \mathrm{C}$, and the experiment above was repeated. The results are shown in Figure 7a. The contact angles fluctuated between 150 and $155^{\circ}$, and the sliding angles were about $10^{\circ}$. No obvious difference compared with the surface before the thermal treatment was observed. Because the glass transition temperature $\left(\mathrm{T}_{\mathrm{g}}\right)$ of Su-8 is greater than $200{ }^{\circ} \mathrm{C}$, the contact angle and sliding angles will not be affected after heating at lower temperatures. This result confirms that the T-topping features were not altered and the water repellency of the 
structured surfaces was stable, even when subjected to very high temperatures. The sample showed a high temperature bearing capacity. The surface maintained superhydrophobicity after exposure to high temperatures, so the surface can be applied in high temperature situations.

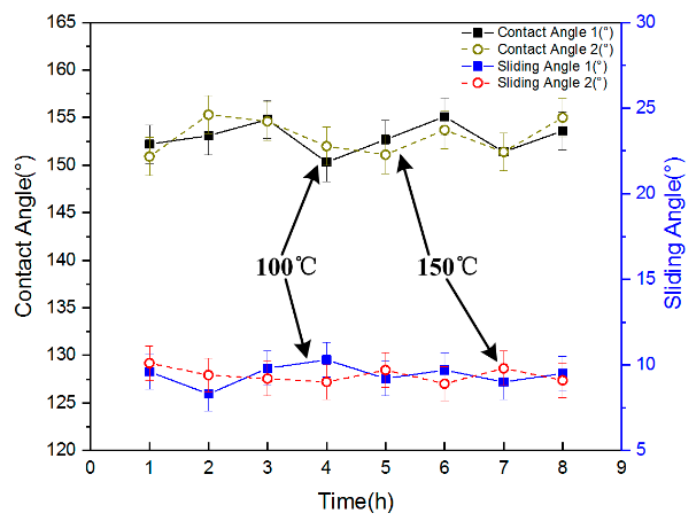

(a)

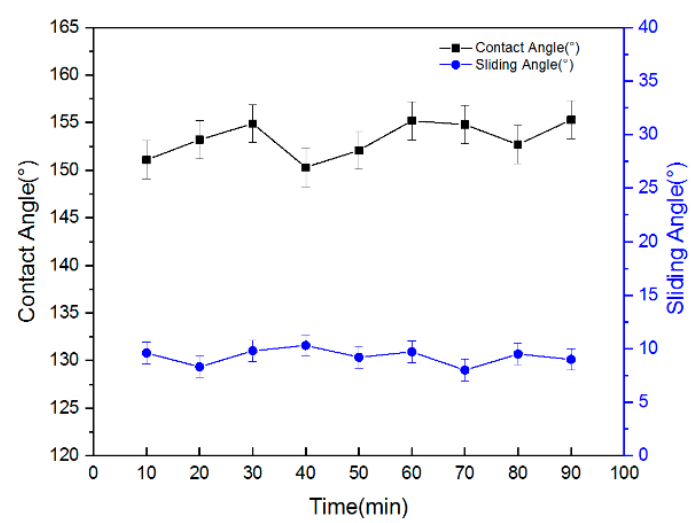

(b)

Figure 7. (a) The contact angles and sliding angles of the surface after high temperature thermal treatment. Contact angle 1 and sliding angle 1 are the results of the surface after $100{ }^{\circ} \mathrm{C}$ thermal treatment, contact angle 2 and sliding angle 2 are the results of surface after $150{ }^{\circ} \mathrm{C}$ thermal treatment.

(b) The contact angle of surface after ultraviolet (UV) irradiation.

In the UV durability tests, the sample was irradiated with UV for up to $90 \mathrm{~min}$, and the contact angles of the sample were measured every $10 \mathrm{~min}$. The result is shown in Figure $7 \mathrm{~b}$. The contact angles fluctuated between 150 and $155^{\circ}$, and the sliding angles were about $10^{\circ}$. No obvious difference was observed compared with the surface before UV irradiation. The surface maintained superhydrophobicity after UV irradiation for a long time, showing an excellent UV bearing capacity.

The relationship between the static contact angle and low temperature was investigated. The sample was cooled on the refrigeration table, and the side view of the water droplet and the corresponding temperature were recorded. As shown in Figure 8, the static contact angles changed slightly when the temperature fell from 10 to $-5^{\circ} \mathrm{C}$. Because the cooling process was rapid, the water drop did not freeze. Because the condensation of the water from the air would impact the wettability and cause the switch from Cassie-Baxter to Wenzel, we controlled the humidity of the air using the thermostat. The humidity was $30 \%$. When the temperature fell from 10 to $-5{ }^{\circ} \mathrm{C}$, the static contact angles decreased to less than $10^{\circ}$. The surface maintained hydrophobicity when the temperature decreased, so the structure has a strong ability to adapt to falling temperatures.

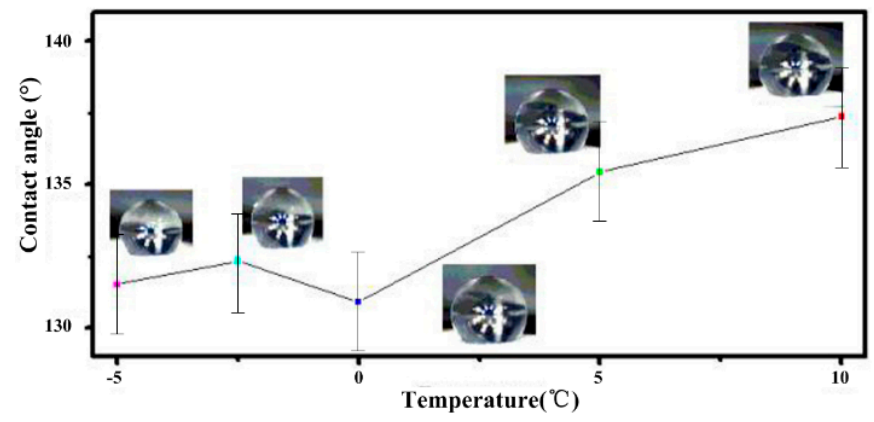

Figure 8. The water contact angles for the prepared surface during the cooling process as a function of temperature. When the temperature decreased from 10 to $-5{ }^{\circ} \mathrm{C}$, the static contact angles decreased from $137.5 \pm 2^{\circ}$ to $131.4 \pm 2^{\circ}$. 


\section{Conclusions}

Inspired by the micro structure of the Salvinia molesta leaf, we designed and fabricated a periodic hollowed-out pyramid microstructure with excellent superhydrophobicity by combining capillary-induced self-assembly and photolithography technology. SU-8 photoresist was used as the structural material in this fabrication. To maintain the droplet on the micropillar array in Cassie state, T-topping pillars were constructed to improve the geometrical edge angle. The evaporation-induced assembly collapsed the pillar and formed the hollowed-out pyramid structure during the structure release step. The water contact angle of the surface was $154 \pm 2^{\circ}$ and the sliding angle of the surface was $10 \pm 1^{\circ}$. Additionally, the prepared surface showed excellent wettability after long exposure to high temperatures and ultraviolet irradiation, and the contact angle of the surface fluctuated slightly when the temperature dropped.

For the hollowed-out pyramid-like surface, considerable space remained between the micro pillars, and the interspace surrounded by the hollowed-out pyramid-like structures was better for air retention, so the surface has potential to retain air under water. Compared with the previous durable superhydrophobic surfaces [39-45], the water contact angle of the prepared surface only reached superhydrophobicity, and the sliding angle of the prepared surface must be improved. The durability against mechanical abrasion, chemical stability, and organic solvents need further research. However, the prepared surface attained superhydrophobicity by changing the micro structure of the basement materials without any fluorinated alkyl silane or modified silica nanoparticles. The surface demonstrated stable wettability against high temperatures, cooling, and UV resistance, which are very important for practical application. Additionally, the hollowed-out pyramid-like structures can be fabricated by other materials with good mechanical properties. The surface has the potential for self-cleaning and drag reduction under water. Further research may focus on the wettability of the micro structure array boundary, because this region will inject water to the surface if the surface becomes immersed in water.

Author Contributions: Weipeng Luo designed the research and wrote the manuscript. Weipeng Luo and Bin Yu conducted the experiments, and fabricated the samples. Dingbang Xiao, Meng Zhang, Xuezhong Wu and Guoxi Li contributed to the discussion and reviewed the manuscript.

Acknowledgments: This research received no external funding. The authors would like to thank Hongjuan Cui, Jian Zhou, Chaoguang Wang, Xinghua Wang, Qiang Xu, Yi Xu, Yuan Lu, Zhaoxin Song, Xiangming Xu of National University of Defense and Technology Microsystem Laboratory for their support.

Conflicts of Interest: The authors have no conflict of interest.

\section{References}

1. Jiang, C.G.; Xin, S.C.; Wu, C.W. Drag reduction of a miniature boat with superhydrophobic grille bottom. AIP Adv. 2011, 1, 032148. [CrossRef]

2. Hoefnagels, H.F.; Wu, D.; de With, G.; Ming, W. Biomimetic Superhydrophobic and Highly Oleophobic Cotton Textiles. Langmuir 2007, 23, 13158-13163. [CrossRef] [PubMed]

3. Ceccio, S.L. Friction Drag Reduction of External Flows with Bubble and Gas Injection. Annu. Rev. Fluid Mech. 2010, 42, 183-203. [CrossRef]

4. Shen, X.; Ceccio, S.L.; Pertin, M. Effect of bubble size on micro-bubble drag reduction. Exp. Fluids 2006, 41, 415-424. [CrossRef]

5. Choi, C.H.; Kim, C.J. Effective slip and friction reduction in nanograted superhydrophobic microchannels. Phys. Rev. Lett. 2006, 18, 781-482. [CrossRef]

6. Min, T.; Yoo, J.Y.; Choi, H.; Joseph, D.D. Drag reduction by polymer additives in a turbulent channel flow. J. Fluid Mech. 2003, 486, 213-238. [CrossRef]

7. Ou, J.; Perot, B.; Rothstein, J.P. Laminar drag reduction in microchannels using ultrahydrophobic surfaces. Phys. Fluids 2004, 16, 4635-4643. [CrossRef]

8. Yanjing, T.; Weiping, C.; Haifeng, Z.; Pujun, L.; Xiaowei, L. One-step Hydrothermal Method to Fabricate Drag Reduction Superhydrophobic Surface on Aluminum Foil. Appl. Surf. Sci. 2018, 446, 230-235. 
9. Deke, L.; Zhiguang, G. Metal-Organic Framework Superhydrophobic Coating on Kevlar Fabric with Efficient Drag Reduction and Wear Resistance. Appl. Surf. Sci. 2018, 443, 548-557.

10. Barthlott, W.; Schimmel, T.; Wiersch, S.; Koch, K.; Brede, M.; Barczewski, M.; Walheim, S.; Weis, A.; Kaltenmaier, A.; Leder, A.; et al. The Salvinia paradox: Superhydrophobic surfaces with hydrophilic pins for air retention under water. Adv. Mater. 2010, 22, 2325-2328. [CrossRef] [PubMed]

11. Boncheva, M.; Bruzewicz, D.A.; Whitesides, G.M. Millimeter-Scale Self-Assembly and its applications. Pure Appl. Chem. 2003, 75, 621-630. [CrossRef]

12. Stauth, S.A.; Parviz, B.A. Self-Assembled Single-CrystalSilicon Circuits on Plastic. Proc. Natl. Acad. Sci. USA 2006, 103, 13922-13927. [CrossRef] [PubMed]

13. Grzybowski, B.A.; Stone, H.A.; Whitesides, G.M. Dynamic Self-Assembly of Magnetized, Millimetre-Sized Objects Rotating at a Liquid Air Interface. Nature 2000, 405, 1033-1036. [CrossRef] [PubMed]

14. Tien, J.; Terfort, A.; Whitesides, G.M. Microfabrication through Electrostatic Self-Assembly. Langmuir 1997, 13, 5349-5355. [CrossRef]

15. Adams, M.; Dogic, Z.; Keller, S.L.; Fraden, S. Entropically Driven Microphase Transitions in Mixtures of Colloidal Rods and Spheres. Nature 2007, 393, 349-352. [CrossRef]

16. Bowden, N.; Terfort, A.; Carbeck, J.; Whitesides, G.M. Self-Assembly of Mesoscale Objects into Ordered Two Dimensional Arrays. Science 1997, 276, 233-235. [CrossRef] [PubMed]

17. Chandra, D.; Yang, S.; Soshinsky, A.A.; Gambogi, R.J. Biomimetic Ultrathin Whitening by Capillary-ForceInduced Random Clustering of Hydrogel Micropillar Arrays. ACS Appl. Mater. Interfaces 2009, 1, 1698-1704. [CrossRef] [PubMed]

18. Chandra, D.; Yang, S. Stability of High-Aspect-Ratio Micropillar Arrays against Adhesive and Capillary Forces. Acc. Chem. Res. 2010, 43, 1080-1091. [CrossRef] [PubMed]

19. Chandra, D.; Yang, S. Capillary-Force-Induced Clustering of Micropillar Arrays: Is It Caused by Isolated Capillary Bridges or by the Lateral Capillary Meniscus Interaction Force? Langmuir 2009, 25, 10430-10434. [CrossRef] [PubMed]

20. Zeniou, A.; Ellinas, K.; Olziersky, A.; Gogolides, E. Ultra-high aspect ratio Si nanowires fabricated with plasma etching: Plasma processing, mechanical stability analysis against adhesion and capillary forces and oleophobicity. Nanotechnology 2014, 25, 035302. [CrossRef] [PubMed]

21. Kang, S.H.; Pokroy, B.; Mahadevan, L.; Aizenberg, J. Control of shape and size of nanopillar assembly by adhesion-mediated elastocapillary interaction. ACS Nano 2010, 4, 6323-6331. [CrossRef] [PubMed]

22. Chen, B.; Riche, C.T.; Lehmann, M.; Gupta, M. Responsive polymer welds via solution casting for stabilized self-assembly. ACS Appl. Mater. Interfaces 2012, 4, 6911-6916. [CrossRef] [PubMed]

23. Hu, Y.; Lao, Z.; Cumming, B.P.; Wu, D.; Li, J.; Liang, H.; Chu, J.; Huang, W.; Gu, M. Laser printing hierarchical structures with the aid ofcontrolled capillary-driven self-assembly. Proc. Natl. Acad. Sci. USA 2015, 112, 6876-6881. [CrossRef] [PubMed]

24. Hung, K.Y.; Hu, H.T.; Tseng, F.G. Application of 3D glycerol-compensated inclined-exposure technology to an integrated optical pick-up head. J. Micromech. Microeng. 2004, 14, 975-983. [CrossRef]

25. Kaminaga, M.; Ishida, T.; Omata, T. Fabrication of Pneumatic Microvalve for Tall Microchannel Using Inclined Lithography. Micromachines (Basel) 2016, 12, 224. [CrossRef]

26. Zhu, Z.; Zhou, Z.F.; Huang, Q.A.; Li, W.H. Modeling, simulation and experimental verification of inclined UV lithography for SU-8 negative thick photoresists. J. Micromech. Microeng. 2008, 18, 125017-125027. [CrossRef]

27. Ling, Z.G.; Lian, K. New fabrication techniques of SU-8 fiber holder with cantilever-type elastic microclips by inclined UV lithography in water using single Mylar mask. Microsyst. Technol. 2010, 16, 405-410. [CrossRef]

28. Zhou, Z.F.; Huang, Q.A.; Zhu, Z.; Li, W.H. An efficient simulation system for inclined UV lithography processes of thick SU-8 photoresists. IEEE Trans. Semicond. Manuf. 2011, 24, 294-303. [CrossRef]

29. Guo, Z.G.; Liu, W.; Su, B.L. Superhydrophobic surface: From natural to biomimetic to functional. J. Colloid Interface Sci. 2011, 353, 335-355. [CrossRef] [PubMed]

30. Liu, K.; Jiang, L. Bio-inspired design of multiscale structures for function integration. Nano Today 2011, 6, 155-175. [CrossRef]

31. Jeevahan, J.; Chandrasekaran, M.; Joseph, G.B.; Durairaj, R.B.; Mageshwaran, G. Superhydrophobic surfaces: A review on fundamentals, applications, and challenges. J. Coat. Technol. Res. 2018, 15, 231-250. [CrossRef]

32. Mobarakeh, L.F.; Jafari, R.; Farzaneh, M. The ice repellency of plasma polymerized hexamethyldisiloxane coating. Appl. Surf. Sci. 2013, 284, 459-463. [CrossRef] 
33. Wang, H.; He, G.; Tian, Q. Effects of nano-fluorocarbon coating on icing. Appl. Surf. Sci. 2012, 258, 7219-7224. [CrossRef]

34. Jullok, N.; Martínez, R.; Wouters, C.; Luis, P.; Sanz, M.T.; Van der Bruggen, B. A biologically inspired hydrophobic membrane for application in pervaporation. Langmuir 2013, 29, 1510-1516. [CrossRef] [PubMed]

35. Kujawa, J.; Kujawski, W. Functionalization of Ceramic Metal Oxide Powders and Ceramic Membranes by Perfluroalkylsilanes and Alkylsilanes Possessing Different Reactive Groups: Physicochemical and Tribological Properties. ACS Appl. Mater. Interfaces 2016, 8, 7509-7521. [CrossRef] [PubMed]

36. Kujawa, J.; Cerneaux, S.; Kujawski, W.; Knozowska, K. Hydrophobic Ceramic Membranes for Water Desalination. Appl. Sci. 2017, 7, 402. [CrossRef]

37. Tuteja, A.; Choi, W.; Ma, M.; Mabry, J.M.; Mazzella, S.A.; Rutledge, G.C.; McKinley, G.H.; Cohen, R.E. Designing Superoleophobic Surfaces. Science 2007, 318, 1618-1622. [CrossRef] [PubMed]

38. Liu, T.; Kim, C.J. Turning a surface superrellent even to completely wetting liquids. Science 2014, 346, 1096-1100. [CrossRef] [PubMed]

39. Ellinas, K.; Tserepi, A.; Gogolides, E. Durable superhydrophobic and superamphiphobic polymeric surfaces and their applications: A review. Adv. Colloid Interface Sci. 2017, 250, 132-157. [CrossRef] [PubMed]

40. Milionis, A.; Loth, E.; Bayer, I.S. Recent advances in the mechanical durability of superhydrophobic materials. Adv. Colloid Interface Sci. 2016, 229, 57-79. [CrossRef] [PubMed]

41. Zeng, C.; Wang, H.; Zhou, H.; Lin, T. Self-cleaning, Superhydrophobic Cotton Fabrics with Excellent Washing Durability, Solvent Resistance and Chemical Stability Prepared from SU-8 Derived Surface Coating. RSC Adv. 2015, 5, 61044-61050. [CrossRef]

42. Zimmermann, J.; Reifler, F.A.; Fortunato, G.; Gerhardt, L.C.; Seeger, S. A Simple, One-Step Approach to Durable and Robust Superhydrophobic Textiles. Adv. Funct. Mater. 2010, 18, 3662-3669. [CrossRef]

43. Wu, L.; Zhang, J.; Li, B.; Fan, L.; Li, L.; Wang, A. Facile preparation of super durable superhydrophobic materials. J. Colloid Interface Sci. 2014, 432, 31-42. [CrossRef] [PubMed]

44. Zhang, J.; Seeger, S. Superoleophobic coatings with ultralow sliding angles based on silicone nanofilaments. Angew. Chem. Int. Ed. 2011, 50, 6652-6656. [CrossRef] [PubMed]

45. Wong, W.S.Y.; Stachurski, Z.H.; Nisbet, D.R.; Tricoli, A. Ultra-Durable and Transparent Self-Cleaning Surfaces by Large-Scale Self-Assembly of Hierarchical Interpenetrated Polymer Networks. ACS Appl. Mater. Interfaces 2016, 8, 13615-13623. [CrossRef] [PubMed]

46. Bai, N.; Li, Q.; Dong, H.; Tan, C.; Cai, P.; Xu, L. A versatile approach for preparing self-recovering superhydrophobic coatings. Chem. Eng. J. 2016, 293, 75-81. [CrossRef]

47. Wang, H.; Xue, Y.; Ding, J.; Feng, L.; Wang, X.; Lin, T. Durable, self-healing superhydrophobic and superoleophobic surfaces from fluorinated-decyl polyhedral oligomeric silsesquioxane and hydrolyzed fluorinated alkyl silane. Angew. Chem. Int. Ed. 2011, 50, 11433-11436. [CrossRef] [PubMed]

48. Lü, C.; Yin, X.; Wang, M. Fabrication of high aspect ratio metallic microstructures on ITO glasssubstrate using reverse-side exposure of SU-8. Sens. Actuators A Phys. 2007, 136, 412-416. [CrossRef]

49. Chuang, Y.J.; Tseng, F.G.; Lin, W.K. Reduction of diffraction effect of UV exposure on SU-8 negative thickphotoresist by air gap elimination. Microsyst. Technol. 2002, 8, 308-313. [CrossRef]

50. Kang, W.J.; Rabe, E.; Kopetz, S.; Neyer, A. Novel exposure methods based onreflection and refraction effects inthe field of SU-8 lithography. J. Micromech. Microeng. 2006, 16, 821-831. [CrossRef]

51. Cassie, A.B.D.; Baxter, S. Wettability of porous surfaces. J. Trans. Faraday Soc. 1944, 40, 546-551. [CrossRef]

52. Chen, B.; Seidel, S.; Hori, H.; Gupta, M. Self-Assembly of Pillars Modified with Vapor Deposited Polymer Coatings. ACS Appl. Mater. Interfaces 2011, 3, 4201-4205. [CrossRef] [PubMed]

(C) 2018 by the authors. Licensee MDPI, Basel, Switzerland. This article is an open access article distributed under the terms and conditions of the Creative Commons Attribution (CC BY) license (http:/ / creativecommons.org/licenses/by/4.0/). 